\title{
Double inferior vena cava with multiple interconnections - a rare case report
}

\author{
Sushil Kumar ${ }^{1 *}$, Ritwik Baidya ${ }^{1}$, Prakash Baral² \\ 'Division of Anatomy, Department of Radiology, Weill Cornell medicine, 1300 York Avenue, New York, NY 10065, ${ }^{2}$ Professor of \\ Anatomy, Gandaki medical college and teaching hospital, Pokhara, Nepal
}

\begin{abstract}
Duplication of the inferior vena cava (IVC) has been estimated to occur in $0.2 \%$ to $3 \%$ of the population. Although rare, the presence of double inferior vena cava is important to recognize as it has important implications. Diagnostic confusion in interpreting imaging results can arise when a venous anomaly is mistaken for a pathologic process like lymphadenopathy. If such patient were to need an IVC filter placement, separate filters would be required, one for the right and one for the left IVCs. A vascular surgeon would need to be aware of these anomalies to perform safe surgery of the retroperitoneal organs. We present a case of duplicated IVC, which was observed during routine dissection of a 58-year-old male cadaver. Left IVC was communicating with left renal vein superiorly. The left renal vein was running obliquely behind the abdominal aorta. Also, the left IVC was connected to right IVC by one transverse anastomosing vessel. The two-retroaortic communication between right and left IVC make this case report unique.
\end{abstract}

Keywords: Double, inferior vena cava, renal vein, retroaortic

\section{Correspondence to:}

Dr Sushil Kumar

${ }^{1}$ Division of Anatomy, Department of Radiology, Weill Cornell medicine, 1300 York Avenue, New York, NY 10065

E-mail: sushilbhu2001@yahoo.co.in

Submitted: July 27, 2020

Accepted: October 19, 2020

To cite: Kumar S, Baidhya R, Baral P. Double inferior vena cava with multiple interconnections - a rare case report. JGMC Nepal. 2020;13(2):192-4.

DOI: 10.3126/jgmcn.v13i2.30356

\section{INTRODUCTION}

The inferior vena cava (IVC) conveys blood to the right atrium from almost all the structures below the diaphragm. It is formed by the union of right and left common iliac veins at $\mathrm{L} 5$ vertebral level, ascends anterior to the vertebral column to the right of the aorta, grooves the posterior surface of liver, passes through the central tendon of the diaphragm and drains into the right atrium. Incidence of double IVC has been estimated to occur in $0.2 \%$ to $3 \%$ of the population and occur due to the persistence of left supracardinal veins and its anastomosis with the right IVC. ${ }^{1,2}$ Most of the double IVC remain clinically silent and found accidently for other reasons. There has been report of increased incidence of deep vein thrombosis in such patient. ${ }^{3}$ During surgery over lumbar vertebra and pelvic region such anomaly could produce unexpected hemorrhage. ${ }^{4}$ Knowledge of these anatomical variations is necessary to reduce surgical risk and to determine strategy in interventional radiology. We are presenting a case report in which double inferior cava is associated with multiple interconnections. Embryological basis and clinical significance has also been discussed.

\section{CASE REPORT}

During dissection for medical students at Weill Cornell Medicine New York anatomy lab, on a 58-year-old male cadaver we observed double IVC. The right IVC was $21.66 \mathrm{~mm}$ in diameter whereas the left IVC was almost half the size $111.18 \mathrm{~mm}$ in 
diameter). The right common iliac vein joined the left common iliac vein at the level of fifth lumbar vertebra and formed the right IVC. The left IVC had a superior connection with the left renal vein. It was also connected to the right IVC by two communicating anastomosing veins, of which the superior one was more obliquely placed than the inferior one, which was more horizontally placed. Superior anastomosing vein was $9.15 \mathrm{~mm}$ in diameter and $34.56 \mathrm{~mm}$ in length whereas inferior one was $13.39 \mathrm{~mm}$ in diameter and $20.05 \mathrm{~mm}$ in length. Both the anastomosing vessels were retroaortic. The right IVC was $70.01 \mathrm{~mm}$ in length from beginning to the upper margin of oblique anastomosis. The left IVC was $89.88 \mathrm{~mm}$ in length from its beginning to the upper margin of oblique anastomosis.

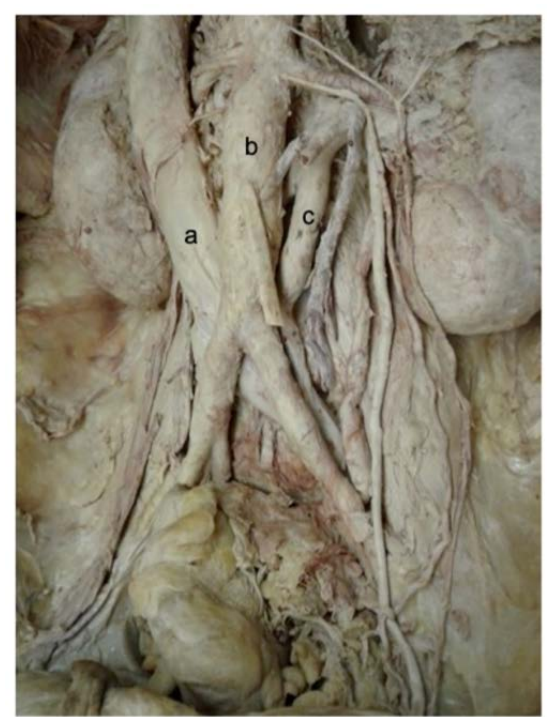

Fig. 1: Double IVC with abdominal aorta between them. a Right IVC, b - Abdominal aorta, c - Left IVC

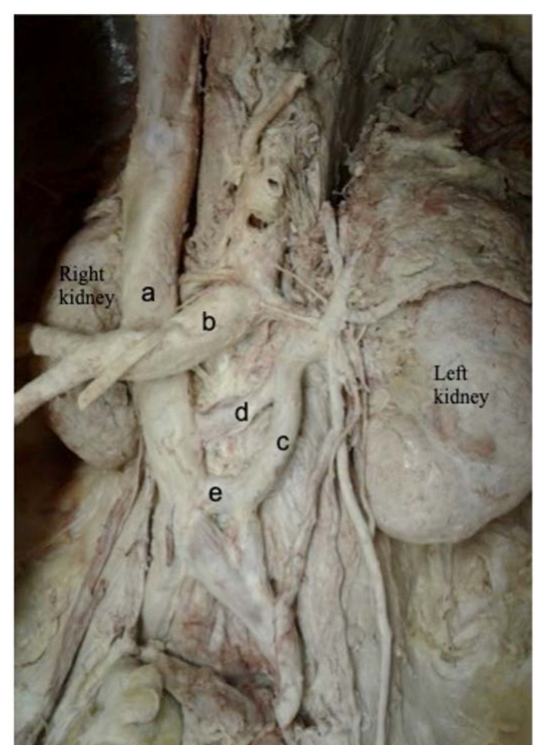

Fig. 2: Double IVC (common iliac arteries along with the distal abdominal aorta cut and reflected to the right to show anastomosing veins). a - right inferior vena cava, b - abdominal aorta, c - left inferior vena cava, d - oblique anastomosis between right and left inferior vena cava, e transverse anastomosis between right and left inferior vena cava

\section{DISCUSSION}

IVC is a composite vein. Its formation is a result of the development, regression, anastomosis and replacement of the three-paired embryonic veins. ${ }^{4,5}$ In order of appearance, they are the posterior cardinal vein, the subcardinal vein and the supracardinal vein. This process begins at the sixth week of gestation and is completed by the tenth week. The posterior cardinal veins develop on the posterior aspect of the embryo. While most of it undergoes regression, the distal part persists and form common iliac vein. This is followed by the appearance of the subcardinal veins anterior and medial to the posterior cardinal vein. The right subcardinal vein persist and form the suprarenal part of the inferior vena cava, while the left subcardinal vein completely regresses. Subsequently, the supracardinal veins appear dorsal to the subcardinal veins. The right supracardinal vein forms the infrarenal segment of the IVC, while the left one regresses. Therefore, the normal IVC develops from four embryonic veins: 1 . The infrarenal segment from the right supracardinal vein, 2 . The renal segment from the right supracardinal anastomosis, 3. The suprarenal segment from the right subcardinal vein and 4 . The hepatic segment from the right vitelline vein.

The anomalies of the IVC arise from the failure of normal embryogenesis. The most commonly described anomalies of IVC include circumaortic left renal vein (1.5\%-8.7\%), azygos or hemiazygos continuation of IVC $(0.6 \%)$, retroaortic left renal vein $(2.1 \%)$, double IVC $(0.2 \%-3 \%)$ and isolated left sided IVC $(0.2 \%-0.5 \%) .{ }^{4}$ The double IVC is considered to be due to the persistence of both supracardinal veins. ${ }^{5}$ The duplicated left IVC usually drains into the left renal vein, which then crosses anterior to aorta and joins the right IVC in a normal fashion. ${ }^{6}$ In our present case report, persistence of left supracardinal vein which should have been disappeared, is responsible for the left IVC. Most of the anastomosis between right and left supracardinal veins regress, but sometime they persist (as in our case report) and cause multiple interconnections between right and left IVC.

It has been reported from radiological study that the IVC anomalies were more common in men (39 of 3821 cases) than in women (12 of 2473 cases); men/women ratio is $2: 1{ }^{4}$ The result from our study was in line with these findings.

There are numerous case reports of the duplicated IVC published in the literature. Most cases are incidentally diagnosed on imaging for other reasons. However, this venous 
anomaly has significant clinical implications, especially during retroperitoneal surgery and venous interventional radiology. Thus, familiarity with these anatomical anomalies is vital for vascular surgeons, spinal surgeon, urologists to reduce risk of serious hemorrhage during surgical treatment and to avoid operative complications. ${ }^{7-10}$ These variations cannot be classed as pathological findings, and should not be confused with lymphomas and has to differ from secondary collateral venous pathways. ${ }^{11}$ Detailed knowledge of these anomalies is crucial for IVC filter placement, spermatic cord embolization, and adrenal or renal venous sampling., ${ }^{2,8}$

\section{CONCLUSION}

Anomalies of the IVC and renal veins occur infrequently but if unidentified can lead to misdiagnosis, significant morbidity during surgical exploration.

\section{CONFLICT OF INTEREST}

The authors declare that they have no conflict of interest

\section{INFORMED CONSENT:}

Not required

\section{REFERENCES:}

1. Adachi B. Japanes venous system: The imperial Japanese University of Kyoto. 1940;216-266.

2. Yano R, Hayakawa D, Emura S, Chen H, Ozawa Y, Taguchi $\mathrm{H}$, Shoumura S. Two cases of the double inferior venaecavae. Okajimas Folia Anat Jpn. 2000;77:133-136. DOI: 10.2535/ofaj1936.77.4_133 PMID: 11111381.

3. Anne N, Pallapothu R, Holmes R, Johnson MD. Inferior venacava duplication and deep venous thrombosis: case report and review of literature. Ann Vasc Surg.
2005;19:740-3. DOI: 10.1007/s10016-005-5674-6 PMID: 16034513.

4. Inamasu J, Guiot BH. Laparoscopic anterior lumbar interbody fusion: a review of outcome studies. Minim Invasive Neurosurg. 2005;48:340-7. DOI: $10.1055 / \mathrm{s}-$ 2005-915634 PMID: 16432783.

5. Mathews R, Smith PA, Fishman EK, Marshall FF. Anomalies of the inferior vena cava and renal veins: embryologic and surgical considerations. Urology. 1999;53:873-80. DOI: 10.1016/S00904295(99)00007-2

6. Kumar S. An anomaly of inferior vena cava- cases report. KUMJ. 2006; 4:253-5.

7. Babaian RJ, Johnson DE. Major venous anomalies complicating retroperitoneal surgery. South Med J. 1979;72:1254-1258. 10.1097/00007611-19791000000012 PMID: 482980.

8. Meyer DR, Huggle H, Andresen R, Huppe T, Friedrich M. Segmental variants of the inferior vena cava-manifestations with embryological correlation in differentiation from secondary venacava occlusion. Rontgenpraxis. 2001;54:101-3.

9. Shingleton WB, Hutton M, Resnick MI. Duplication of inferior venacava: its importance in retroperitoneal surgery. Urology. 1994;43:113-5. DOI: 10.1016/S00904295(94)80281-5

10. Trigaux JP, Vandroogenbroek S, De Wispelaere JF, Lacrosse M, Jamart J. Congenital anomalies of the inferior vena cava and left renal vein: evaluation with spiral CT. J Vasc Interv Radiol. 1998; 9:339-45. 10.1016/ S1051-0443(98)70278-7

11. Bastounis E, Pikoulis E, Leppaniemi A, Maltezos C, Milas F, Alexiou D. Anomalous inferior vena cava complicating abdominal aortic aneurysmectomy. J Cardiovasc Surg (Torino).1997;38:367-9. 